\title{
A CRISPR-based ultrasensitive assay redefines "undetectable" SARS-CoV-2 antibodies in kidney transplant recipients after COVID-19 vaccination
}

\section{Yanan Tang}

Sichuan University

\section{Turun Song}

West China Hospital, Sichuan University

Lu Gao

Sichuan University

\section{Saifu Yin}

West China Hospital, Sichuan University

\section{Min Ma}

West China Hospital, Sichuan University

\section{Yun Tan}

Sichuan University

\section{Lijuan Wu}

West China Hospital, Sichuan University

Tao Lin

West China Hospital, Sichuan University

Feng Li ( $\square$ fli-scu@outlook.com )

Sichuan University https://orcid.org/0000-0002-2616-5343

\section{Article}

Keywords:

Posted Date: January 27th, 2022

DOI: https://doi.org/10.21203/rs.3.rs-1278355/v1

License: (c) (i) This work is licensed under a Creative Commons Attribution 4.0 International License. Read Full License

Version of Record: A version of this preprint was published at Nature Communications on August 9th, 2022. See the published version at https://doi.org/10.1038/s41467-022-32371-4. 


\section{Abstract}

An ultrasensitive assay for the detection of antibodies to SARS-CoV-2 is critically needed for evaluating the adaptive humoral immune response and infection rates in immunocompromised subpopulations. Here, we report an Ultrasensitive CRISPR-based Antibody Detection (UCAD) assay that translates the detection of serum antibodies against the receptor binding domain (RBD) of SARS-CoV-2 spike protein into CRISPR-based nucleic acid testing in a homogeneous solution and is thus 10,000 times more sensitive than the commercial immunoassay. The UCAD assay, which has been validated with 65 clinical anti-RBD-positive and 72 anti-RBD-negative sera collected from the general population, achieves $100 \%$ sensitivity and $97.2 \%$ specificity. We finally deployed UCAD to evaluate the levels of serum anti-RBD IgG and IgM in a cohort of 85 vaccinated kidney transplant recipients (KTRs), an especially vulnerable patient population with reported seroconversion rates of only $4-48 \%$. Among the 85 vaccinated KTRs, UCAD successfully identified 68 seroconversion positive sera that were previously determined to contain "undetectable" levels of anti-SARS-CoV-2 using a clinical chemiluminescent immunoassay (CLIA) and has revealed significant differences in the levels of plasmablasts, type-2 T helper (Th2) cells, and type-17 T helper (Th17) cells between the UCAD-identified seroconversion positive and negative groups. As UCAD is a solution-based ultrasensitive assay that does not require specialized equipment or tedious operational and washing steps, we anticipate that it will find wide applications for clinical uses in both centralized laboratories and point-of-care settings.

\section{Introduction}

Coronavirus disease 2019 (COVID-19) caused by severe acute respiratory syndrome coronavirus 2 (SARSCoV-2) was declared a pandemic by the World Health Organization (WHO) on 11th March 2020. ${ }^{1}$ The urgent requirements for sensitive and specific assays to detect viral infections and subsequent immune responses at both the individual and population levels have offered tremendous opportunities for accelerating the development and validation of new diagnostic techniques for clinical uses. CRISPRbased point-of-care tests (POCTs) are among the most attractive tools for diagnosing COVID-19 infections via the detection of viral RNA under resource-limited conditions. ${ }^{2,3}$ Currently, both CRISPRCas13 specific high-sensitivity enzymatic reporter unlocking (SHERLOCK) and Cas12-mediated DNA endonuclease-targeted CRISPR trans reporter (DETECR) have been approved by the United States Food and Drug Administration (FDA) for commercial uses through Emergency Use Authorization (EUA). ${ }^{3-5}$ Despite remarkable success as nucleic acid tests (NATs), CRISPR-Cas systems have not been exploited for the sensitive detection of anti-SARS-CoV-2 antibodies, another important class of biomarkers for estimating the seroprevalence of infection, monitoring the progress of pandemic, and assessing the protective humoral immunity of infected individuals and recipients of vaccination. ${ }^{6-8}$ Although many conventional immunoassays, such as enzyme-linked immunosorbent assay (ELISA) and chemiluminescence immunoassay (CLIA), have been deployed for measuring anti-SARS-CoV-2 antibodies in the general population, ${ }^{9-12}$ the mismatch between seroconversion and effectiveness in immunocompromised patients suggests that current assays might underestimate the humoral response 
in this population. ${ }^{13,14}$ Therefore, simple, ultrasensitive assays with limit-of-detections (LODs) comparable with those of CRISPR-based NATs are critically needed for evaluating the adaptive humoral immune response and infection rates in immunocompromised subpopulations. ${ }^{7,15-17}$

Kidney transplant recipients (KTRs) are an especially vulnerable patient population because of the therapeutic immunosuppression that impairs their immune responses to the COVID-19 vaccine. ${ }^{18}$ Several studies have reported that only $4-48 \%$ of KTRs have detectable anti-spike IgGs after receiving two vaccine doses. ${ }^{18}$ On the other hand, spike specific $T$ cell and $B$ cell-mediated immune responses were still found in KTRs with a negative antibody response after the administration of either mRNA or inactivated COVID19 vaccines. ${ }^{19-22}$ Recent studies have also revealed that KTRs who had a weak response (below the positivity limit) after the second dose were more likely to develop an antibody response after the third dose compared with those without an antibody response. ${ }^{23}$ Collective clinical observations indicate that KTRs might have weak humoral response not detectable by the current techniques. An ultrasensitive antibody test capable of measuring "undetectable" anti-SARS-CoV-2 antibodies defined by conventional techniques will offer valuable information for better understanding the immunity of KTRs and the design of therapeutic immunosuppression and vaccination programs for this population, particularly identifying those who can benefit from additional or booster doses of COVID-19 vaccines.

Herein, we describe the development of an Ultrasensitive CRISPR-based Antibody Detection (UCAD) assay that is 10,000 times more sensitive than the commercial ELISA kits for the detection of anti-SARS-CoV-2 spike protein receptor binding domain (anti-RBD) IgG and IgM in undiluted human serum samples. UCAD was clinically validated using 65 anti-SARS-CoV-2 positive serum samples collected from healthy participants after two doses of inactivated COVID-19 vaccines as positive controls and 17 human serum samples collected before the pandemic as negative controls. The clinical specificity of UCAD was further validated against 55 clinically identified COVID-19 negative serum samples collected during the pandemic. We finally deployed UCAD for the ultrasensitive detection of anti-RBD IgG and IgM in clinical serum samples collected from a cohort of 85 KTRs who received two doses of inactivated COVID-19 vaccine. Using UCAD, we detected $54(63.5 \%)$ anti-RBD IgG positive $\left(\mathrm{IgG}^{+}\right)$and $67(78.8 \%)$ anti-RBD IgM positive $\left(\mathrm{IgM}^{+}\right)$serum samples previously defined to be "undetectable" using the standard CLIA. As expected, the levels of anti-RBD IgG or IgM in KTRs were found to be significantly lower than those in healthy controls. By redefining the detectable antibody levels in KTRs, we were able to reclassify KTRs into anti-RBD-positive ( $\operatorname{lgG}^{+} / \mathrm{lgM}^{+}$, $\left.\operatorname{lgG}^{+} / \mathrm{lgM}^{-}, \operatorname{lgG}^{-} / \operatorname{lgM}^{+}\right)$and anti-RBD-negative (lgG $\left./ / \operatorname{lgM}^{-}\right)$groups. A further comparison between the two groups revealed significant differences in the populations of type-2 T helper (Th2) cells, Th17 cells, and plasmablasts responding to vaccination.

\section{Results}

Design and operation of UCAD assay. The idea of UCAD is to convert the detection of anti-SARS-CoV-2 into the production of a predesigned CRISPR-Cas12a targetable double-stranded DNA (dsDNA) barcode, so that the recombinase polymerase amplification (RPA) and subsequent indiscriminate single-stranded 
DNase (ssDNase) activity of Cas12a can be unleashed by the antibody (Fig. 1a). To achieve this goal, we first designed a dsDNA barcode containing a 20-nucleotide (nt) binding domain to the CRISPR guide RNA (crRNA) (Fig. 1b). To disrupt the binding and activation of Cas12a in the absence of the antibody, we truncated the dsDNA barcode at both the target strand (TS) and nontarget strand (NTS) at the middle of the crRNA binding sequence. The TS and NTS probes were then conjugated with the SARS-CoV-2 spike protein RBD and an anti-human IgG (or IgM) antibody, respectively (Fig. 1c). A short complementary domain was left between the two probes to initiate antibody-induced proximity hybridization (Fig. 1C). Driven by a T4 polymerase, the complete dsDNA barcode forms via primer extension, which serves as a surrogate for the amplified detection of anti-RBD. Experimentally, the optimal length of the complementary domain between the TS and NTS probes was determined to be 6 nt (Supplementary Fig. $\mathrm{S} 1)$. With this design, the melting temperature $\left(T_{\mathrm{m}}\right)$ was estimated to be only $\sim 10^{\circ} \mathrm{C}$, so that no stable duplex could be formed at $37^{\circ} \mathrm{C}$ (Fig. 1C). In the presence of anti-RBD, the binding of anti-human IgG (or $\operatorname{lgM})$ and RBD to the same antibody brings the two DNA probes into proximity and thus leads to the formation of a stable duplex with an estimated $T_{m}$ of $46^{\circ} \mathrm{C}$ (Fig. 1C).

The assay protocol of UCAD consists of three simple steps (Fig. 1a), including 1) antibody-specific primer extension to produce dsDNA barcodes; 2) RPA amplification; and 3) the cleavage of fluorophore-quencher (FQ) labeled ssDNA reporters mediated by CRISPR-Cas12a. Reactions at each step were all performed homogenously at a constant $37^{\circ} \mathrm{C}$ in a single test tube without the need for any separation steps. By carefully optimizing the assay conditions (Supplementary Fig. S2 \& S3), we were able to detect as low as 10 aM anti-RBD human monoclonal antibody, an LOD comparable to those of CRISPR-based NATs (Fig. 1d, Supplementary Fig. S4). The high sensitivity and low background of UCAD were also confirmed using polyacrylamide gel electrophoresis (PAGE) analysis (Supplementary Fig. S5). UCAD was also determined to be highly specific, evidenced by testing against anti-SARS-CoV-2 nucleocapsid ( $\mathrm{N}$ ) human monoclonal and anti-RBD rabbit polyclonal antibodies at concentrations ranging from $10 \mathrm{aM}$ to $1 \mathrm{pM}$ (Fig. 1e and Supplementary Fig. S6). Throughout the concentration ranges, detectable fluorescence signals could only be achieved in the presence of the target anti-RBD human mAb but not the two closely related interfering antibodies.

We next examined whether UCAD would be effective for detecting anti-RBD IgG and IgM in human serum samples. The kinetic curves in Fig. $1 \mathrm{f}$ and $1 \mathrm{~g}$ demonstrate that UCAD could effectively detect both antiRBD IgG and IgM in certified IgG/lgM positive human serum samples obtained commercially, whereas very little fluorescence increases were shown in the negative samples. The sensitivity of UCAD was further compared with standard ELISA using a series of human serum samples prepared by diluting the $\mathrm{lgG} / \mathrm{lgM}$ positive serum using the negative serum with dilution factors ranging from 1 to 100,000 . UCAD was able to detect anti-RBD IgG (Fig. 1h and Fig. S7a) and IgM (Fig. 1i and Fig. S7b) throughout the dilution series. In contrast, the standard ELISA kit worked only for 10-fold diluted serum samples (Fig. 1h and 1i), suggesting that our UCAD assay is at least 10,000 more sensitive than ELISA.

Clinical validation of UCAD. We first validated UCAD against 65 positive clinical human sera that were previously tested by West China Hospital of Sichuan University using a standard total anti-RBD CLIA 
assay and 17 pre-pandemic sera collected in 2019 before the outbreak of COVID-19. All positive samples were collected from healthy participants who had 2 doses of inactivated COVID-19 vaccine. Both IgG and IgM levels against RBD were determined using UCAD (Fig. $2 b$ and $2 \mathrm{c}$ ). Significant differences were found between the positive and pre-pandemic cohorts $(p<0.0001, n=82)$ (Fig. $2 d$ and 2e). To further evaluate the clinical specificity of UCAD, we also obtained a set of sera collected from 55 unvaccinated healthy participants during the pandemic, who have been confirmed to be anti-RBD negative using the standard CLIA test. Comparing with the pre-pandemic cohorts, neither IgG nor IgM levels were significantly different in this cohort (Fig. $2 \mathrm{~d}$ and $2 \mathrm{e}$ ). The 55 negative sera were combined with the 17 pre-pandemic sera as a new negative group to determine the optimal cutoff values for serum anti-RBD IgG and IgM via receiver operating characteristics (ROC) curve analysis (Fig. 2f). The binary outcomes (positive or negative) for anti-RBD IgG and IgM were then combined and compared with the standard CLIA using a confusion matrix (Fig. 2g). The clinical sensitivity and specificity of UCAD $(n=137)$ were determined to be $100 \%$ and $97.2 \%$, respectively. Altogether, within the total 72 pre-pandemic and CLIA-confirmed negative samples, only two samples (one for IgG test and one for lgM test) were found to be false positive with slightly higher fluorescence than the cutoff values and were identified to be outliers using Dixon's $Q$ test.

As a CRISPR-based ultrasensitive assay, UCAD also holds great promise as a POCT for detecting antiSARS-CoV-2 antibodies under resource-limited conditions. We next engineered a lateral flow readout for UCAD by replacing the fluorophore-quencher labeled ssDNA reporter with one labeled with FAM and digoxin (Dig) at the $3^{\prime}$ and 5 ' ends, respectively. We then tested UCAD with a lateral flow readout for the detection of anti-RBD IgG and IgM in clinical sera (more details are provided in Supplementary Section S2). Consistent with our fluorescence-based readout, we detected anti-RBD IgG and IgM in 15 positive clinical sera confirmed by both UCAD and CLIA and 7 pre-pandemic negative sera using the naked eye (Supplementary Fig. S8).

Detection of anti-RBD IgG/lgM in vaccinated KTRs. We studied a cohort of $85 \mathrm{KTRs}$ who had received 2 doses of inactivated COVID-19 vaccine using UCAD (Fig. 3a). All KTRs received a triad immunosuppression regimen composed of mycophenonate mofetil (500 mg bid), steroids (5-10 mg qd), and tacrolimus (TAC) with target trough levels of $5 \mathrm{ng} / \mathrm{mL}$ to $8 \mathrm{ng} / \mathrm{mL}$. More details on demographic and therapeutic information are listed in Supplementary Tables S2 \& S3. Sex and age were found to have no significant impact on the levels of anti-RBD IgG and IgM determined using UCAD (Supplementary Fig. S9).

Serum samples were collected 10 to 60 days (median $=26$ days) after the second dose of vaccine. Consistent with previous reports, ${ }^{18}$ only 5 out of 85 KTRs (5.9\%) were found to be anti-RBD positive using the standard CLIA assays (Supplementary Table S2). In contrast, a total of 73 KTRs (85.9\%) were determined to be anti-RBD positive using UCAD, including $54 \mathrm{IgG}^{+}$and $67 \mathrm{IgM}^{+}$(Fig. 3b and 3c). Spearman correlation suggested that IgM levels of the 73 anti-RBD positive KTRs were positively correlated with sampling time in the range of 10-60 days after the second dose of vaccine $(r=0.3810, p=$ 0.0010) (Supplementary Fig. S10a), while the correlation between IgG levels and sampling time was weaker with a borderline $p$ value $(r=0.2266, p=0.0556)$ (Fig. S11a). The Venn diagrams in Fig. 3d further 
reveal that 48 out of $85 \mathrm{KTRs}$ were $\operatorname{lgG}^{+} / \operatorname{lgM}^{+}(56.5 \%), 6$ were $\operatorname{lgG}^{+} / \operatorname{lgM}^{-}(7.1 \%), 19$ were $\operatorname{lgG}^{-} / \operatorname{lgM}^{+}$ (22.4\%), and 12 were $\operatorname{~gG~}^{-} / \operatorname{lgM}^{-}(14.1 \%)$. Serological levels of $\operatorname{lgG}$ and $\operatorname{lgM}$ were found to be linearly and positively correlated for all 85 KTRs $(p<0.001$, Fig. S12).

For both anti-RBD IgG and IgM, UCAD signals of the KTR cohort were significantly higher than those of the negative controls ( $n=157, p<0.0001$ ) (Fig. 3e and 3f). As expected, substantially reduced humoral immunity was observed in KTRs in response to vaccination, evidenced by the much lower levels of antiRBD IgG and IgM than those of the vaccinated healthy cohort $(n=150, P<0.0001)$ (Fig. 3e and 3f). Several studies suggest that the compromised immunity of KTRs to vaccination was a result of therapeutic immunosuppression. ${ }^{18,24}$ We also observed a negative linear correlation between anti-RBD IgM levels and the trough levels of TAC $(r=-0.2519, p=0.034)$ using Pearson correlation analysis (Fig. 3g), whereas the levels of IgG were not statistically correlated with TAC trough levels (Fig. 3h).

Upon UCAD analysis, we were able to classify the $85 \mathrm{KTRs}$ into the anti-RBD positive group $\left(\mathrm{lgG}^{+} / \mathrm{lgM}^{+}\right.$, $\operatorname{lgG}^{+} / \operatorname{lgM}^{-}$or $\left.\operatorname{lgG}^{-} / \operatorname{lgM}^{+}, \mathrm{n}=73\right)$ and negative group $\left(\mathrm{lgG}^{-} / \mathrm{lgM}^{-}, \mathrm{n}=12\right)$. Through Pearson correlation analysis, we found that the levels of $\operatorname{lgG}$ in the positive group were positively correlated with the percentage composition of lymphocytes in white blood cells (WBCs) counted before $(r=0.2536, p=$ 0.0316 , Fig. $4 b)$ and after vaccination $(r=0.2477, p=0.0387$, Fig. $4 c)$. As lymphocytes are instrumental for antibody production, the positive correlation between $\mathrm{IgG}$ level and lymphocyte percentage indicated the activation of humoral immunity in KTRs after COVID-19 vaccination. This was also consistent with previous observations made in COVID-19 vaccinated healthy populations. ${ }^{25,26}$

Flow cytometric and statistical analysis of blood samples collected from $7 \mathrm{lgG}^{+} / \mathrm{lgM}^{+}$(Supplementary Fig. S13-S19) and $5 \mathrm{Ig} \mathrm{G}^{-} / \mathrm{IgM}^{-}$(Supplementary Fig. S20-S24) KTRs revealed a substantially lower level of plasmablasts in the $\operatorname{lgG}^{-} / \mathrm{IgM}^{-}$cohort (Fig. 4d), while no significant differences were observed in the percentage populations of either total or five subsets of $B$ cells (naïve $B$, transitional $B$, marginal zone (MZ) B, memory B and class-switched B) in lymphocytes (Supplementary Fig. S30-S32). We also found no significant differences between anti-RBD positive KTRs and five vaccinated healthy participants (Supplementary Fig. S25-S29 \& S33). As plasmablasts are a positive indicator for the induction of longlived plasma cell responses upon COVID-19 vaccination, ${ }^{23}$ the observed low level of plasmablasts was well correlated with the undetectable level of anti-RBD in this group of KTRs. In addition to plasmablasts, the cellular analysis of $\mathrm{CD} 4^{+}$cells also showed significant differences in Th2 and Th17 cells in $\mathrm{IgG}^{+} / \mathrm{IgM}^{+}$ and $\mathrm{IgG}^{-} / \mathrm{IgM}^{-}$KTRs (Fig. 4e, $4 \mathrm{f}$ \& Supplementary Fig. S31-S33), suggesting that the abnormality of B cell differentiation and reduced antibody production in anti-RBD negative KTRs might also be related to T cell regulation. ${ }^{24-26}$

\section{Discussion}

Here, we present UCAD, a simple and ultrasensitive assay that is 10,000 times more sensitive than standard ELISA for the detection of serum IgG and IgM against SARS-CoV-2 RBD. Clinically, UCAD was 
determined to be $100 \%$ sensitive and $97.2 \%$ specific based on 137 positive and negative COVID-19 sera collected from the general population. More importantly, in a cohort of 85 vaccinated KTRs, UCAD successfully identified 68 anti-RBD positive sera that were previously defined to contain an "undetectable" level of anti-RBD using the conventional CLIA test (Supplementary Table S2), though fluorescence signals of KTRs were significantly lower than those of the healthy participants. By reclassifying seroconversion positive and negative KTRs using UCAD, we found significant differences in the levels of plasmablasts, Th2 cells, and Th17 cells. These critical clinical findings enabled by UCAD echo the recent clinical observations that the humoral response in KTRs might be underestimated by current tests, ${ }^{11,12,16}$ may initiate more in-depth studies to better understand the humoral immunity of KTRs and shed light on the heterogeneity in response to COVID-19 vaccination. UCAD may also be used directly to guide the design of therapeutic immunosuppression and vaccination programs for KTRs. For example, to identify individuals who are more likely to develop an antibody response after the third booster dose of COVID-19 vaccine and high-risk individuals who are irresponsive to vaccine that convalescent plasma or COVID-19 specific immunoglobulin should be applied as preventive strategy. ${ }^{27}$

UCAD also represents a technical advance and paradigm shift of CRISPR-Dx from solely NATs to ultrasensitive protein analysis. The past three years have witnessed the remarkable success of CRISPRDx as fast and cost-effective POC NATs accessible for patients in low-resource settings. Because UCAD is an "add-on" to existing CRISPR-Dx with a one-step conversion from protein to DNA barcode in a homogeneous solution, it is readily adaptable to existing detection platforms for SHERLOCK or DETECTR without compromising any sensitivity or simplicity. For example, we show here that the fluorescent readout of UCAD could be readily converted to a later flow test with a visual readout (Supplementary Section S2 and Fig. S8). Therefore, compared to existing ultrasensitive protein detection techniques, such as single molecular array (Simoa) $)^{28,29}$ or proximity ligation assays (PLA) ${ }^{15,16,30}$, UCAD works isothermally at $37^{\circ} \mathrm{C}$ without the need for any specialized equipment or tedious operation and washing steps, and thus is particularly attractive for use in resource-constrained conditions, including the opportunity for self-monitoring.

In summary, this work demonstrates the development and clinical uses of UCAD as an ultrasensitive protein assay capable of redefining "undetectable" anti-SARS-CoV-2 antibody levels in sera of KTRs. In future studies, we aim to use this method to track temporal changes in antibody levels in vaccinated individuals to gain better understanding of the immunity of healthy people and KTRs. We will also further engineer UCAD as a broadly applicable POCT for the ultrasensitive detection of clinically important proteins beyond anti-SARS-CoV-2.

\section{Methods}

Sample Collection. This study was approved by the Ethics Committee of West China Hospital of Sichuan University (NO: 2021-110), where all clinical serum samples $(n=222)$ were obtained and analyzed using a standard CLIA test. All research was performed in accordance with relevant guidelines and regulations. All participants have provided informed consent. Blood samples were collected following the standard 
procedure at West China Hospital of Sichuan University. Sera were prepared using serum separator tubes and incubated at room temperature for $1 \mathrm{~h}$. The clot was removed by centrifugation at $1000 \times \mathrm{g}$ for 10 min. The supernatant was collected, aliquoted and stored at $-80^{\circ} \mathrm{C}$ upon usage. Peripheral blood mononuclear cells (PBMCs) were separated from EDTA anticoagulated blood samples of 85 KTRs through density gradient separation, ${ }^{31}$ and the WBCs were counted and differentiated by Sysmex hematology XN modular system.

Preparation of DNA probes for UCAD. All DNA probes and reporters were purchased from Sangon Biotech Co., Ltd. (Shanghai, China) and were purified by high-performance liquid chromatography (HPLC). Sequences and modifications of all DNA or RNA probes are listed in Table S1.

A biotin-streptavidin conjugation protocol was used to prepare all protein-conjugated DNA probes for UCAD. To prepare the RBD-conjugated DNA probe, $25 \mu \mathrm{L}$ of $2.5 \mu \mathrm{M}$ biotinylated TS probe (5'-TTC CTC ACC ATG TCT GAG GTA CTC CTT AAA GGT CGA GCT GGA C-3') was mixed with an equal volume of 2.5 $\mu \mathrm{M}$ streptavidin and incubated at $37^{\circ} \mathrm{C}$ for $30 \mathrm{~min}$. After cooling to room temperature, this reaction mixture was incubated with $50 \mu \mathrm{L}$ of $1.25 \mu \mathrm{M}$ biotinylated RBD of SARS-CoV-2 spike protein (Sino Biological, Beijing, China) at $25^{\circ} \mathrm{C}$ for another $30 \mathrm{~min}$. After conjugation, the RBD-conjugated DNA probes were diluted to $250 \mathrm{nM}$ with Tris-biotin buffer (20 mM Tris-HCl, $0.01 \% \mathrm{BSA}, 1 \mathrm{mM}$ biotin) and stored at $4^{\circ} \mathrm{C}$ until usage. Biotinylated anti-human IgG or IgM (Sangon Biotech, Shanghai, China) conjugated NTS DNA probes (5'-TTG TTG AGG TAA CCA ACT ATT TGT TAC TGT TGC TTG TGG CCG TTT ACG TCG CCG TCC AG-3') were prepared using the same conjugation and storage protocols.

\section{UCAD protocol for the detection of anti-RBD in buffer, certified human sera, and clinical serum samples.}

For a typical UCAD assay, a $50 \mu \mathrm{L}$ reaction mixture containing $5 \mu \mathrm{L}$ serum sample (or buffer), $10 \mathrm{pM}$ RBDTS probe, $10 \mathrm{pM}$ anti-human IgG (or IgM)-NTS probe, $40 \mu \mathrm{M}$ dNTPs and 2 units of T4 polymerase in $1 \times$ NEBuffer ${ }^{\text {TM }} 2$ buffer was incubated at $37^{\circ} \mathrm{C}$ for $20 \mathrm{~min}$. For this reaction mixture, $10 \mu \mathrm{L}$ solution was taken and mixed with reagents provided in the TwistDx ${ }^{T M}$ RPA basic kit (TwistDx, Cambridge, U.K.) and incubated at $37^{\circ} \mathrm{C}$ for 20 min to perform RPA. The RPA amplicon was then mixed with $40 \mathrm{nM}$ Cas $12 \mathrm{a}$ (AltR® A. s. Cas12a (Cpf1) V3, Integrated DNA Technologies, Inc., Coralville, U.S.), 40 nM crRNA (5'-UUA UUU CUA CUC UUG UAG AUC GUC GCC GUC CAG CUC GAC C-3'), and 40 nM FAM-BHQ-1 labeled ssDNA reporter in $100 \mu \mathrm{L} 1 \times$ NEBuffer ${ }^{\mathrm{TM}} 2$ in a 96-well microplate. Fluorescence was measured immediately with a data acquisition rate of one read per minute for 2 hours at $37^{\circ} \mathrm{C}$ using a Cytation 5 cell imaging multimode microplate reader (Biotek) with excitation/emission at 495/520 nm.

For lateral flow strip-based visual readout, the RPA amplicons were incubated with $40 \mathrm{nM}$ Cas $12 \mathrm{a}, 40 \mathrm{nM}$ crRNA and $40 \mathrm{nM}$ FAM-Dig ssDNA reporter in $20 \mu \mathrm{L} 1 \times$ NEBuffer $^{\mathrm{rm}} 2$ at $37^{\circ} \mathrm{C}$ for $30 \mathrm{~min}$, and then loaded on the sample pad of the lateral flow strip with $30 \mu \mathrm{L}$ of $4 \times \mathrm{SSC}$ buffer. Once developed, the results on the lateral flow strips were read directly using the naked eye or captured using a digital camera.

Detection of anti-RBD using standard ELISA test. A commercial ELISA kit (BGI genomics, Shenzhen, China) was used to measure anti-RBD IgG and IgM in certified COVID-19 positive or negative human 
serum samples included in the ELISA kit. The assay was performed according to the instructions provided by the manufacturer. Briefly, $10 \mu \mathrm{L}$ human serum sample (or diluted serum sample) was mixed with $100 \mu \mathrm{L}$ diluent and incubated in the ELISA microplate well at $37^{\circ} \mathrm{C}$ for $30 \mathrm{~min}$. The microplate was then washed 5 times with $350 \mu \mathrm{L}$ washing buffer. Then, $100 \mu \mathrm{L} \operatorname{lgG}$ or IgM enzymatic working solution was added to the microplate and incubated at $37^{\circ} \mathrm{C}$ for $30 \mathrm{~min}$. The microplate was washed again with 5 $\times 350 \mu \mathrm{L}$ washing buffer. To this microplate, $50 \mu \mathrm{L}$ substrate $A$ and $50 \mu \mathrm{L}$ substrate $B$ were added and incubated at $37^{\circ} \mathrm{C}$ for $10 \mathrm{~min}$ in darkness before the addition of $50 \mu \mathrm{L}$ quenching solution. The OD value $(450-620 \mathrm{~nm})$ of each sample was measured immediately after quenching the reaction using Cytation 5 multimode microplate reader.

Flow cytometric analysis of white blood cells. Seven $\operatorname{lgG}^{+} / \operatorname{lgM}^{+} \mathrm{KTRs}_{\mathrm{five}} \operatorname{lgG}^{-} / \operatorname{lgM}^{-} \mathrm{KTRs}$ and five vaccinated healthy participants were recruited for the subpopulation analysis of WBCs by Fluorescence Activated Cell Sorter (FACS). 2 ml EDTA anticoagulated clinical blood samples from each patient were collected. After lysing red blood cells as instructed, ${ }^{31}$ the WBC subsets were characterized by a BD FACSCanto $^{T M}$ II Cytometer after fluorescently labeling the surface antigens. ${ }^{32} 34$ epitopes on the WBC surface were labeled using fluorophore-tagged antibodies, such as FITC, PE, PerCP-CY5.5, PC7, APC, APC-

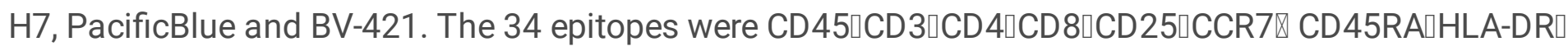

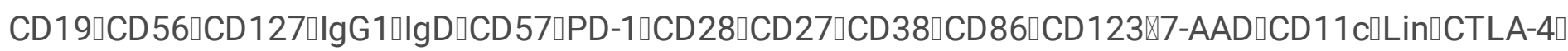

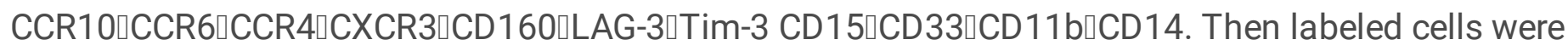
sorted by a BD FACSCanto ${ }^{\text {TM }}$ II Cytometer with antibody panels limited to 8-colors. Data were analyzed by BD FACSDiva ${ }^{\mathrm{TM}}$ with a standardized gating strategy following the ONE-Study protocol (Table S4). ${ }^{33,34}$

Data and statistical analysis. All graphing and statistical analysis were performed in Excel and GraphPad Prism. The unpaired t-test was performed in Prism to compare UCAD signals of anti-RBD IgG and IgM between two cohorts. For comparisons between three or more cohorts, ordinary one-way ANOVA was performed. Dixon's $Q$ test was used to identify outliers. Receiver operating characteristics (ROC) curve analysis was used in Prism to determine the cutoff values of UCAD for positive and negative results. A confusion matrix was performed using Excel to evaluate the performance of UCAD in comparison with the standard CLIA. Nonparametric Spearman correlation analysis was used in Prism to determine the correlation R value between UCAD signals and sampling time. Parametric Pearson correlation analysis was performed to evaluate the linear correlations between UCAD signals and clinical parameters, such as TAC trough levels and lymphocyte levels. For all analyses, a two-tailed $\mathrm{P}$ value $<0.05$ was considered to be statistically significant.

\section{Declarations}

\section{Authors Contributions}

${ }^{\#}$ Y. Tang and T. Song contributed equally to this work. 
F. Li and T. Lin conceived the idea, designed all experiments, and supervised the overall project. Y. Tang and T. Song designed the UCAD assay protocol, performed all UCAD tests for all clinical serum samples, and completed data analysis. Y. Tang and L. Gao developed and optimized probes for the UCAD assay and performed ELISA tests. Yun Tan designed and performed lateral flow tests. Y. Tang, T. Song, and L. Wu designed all clinical studies and performed clinical analysis. S. Yin, M. Ma, and L. Wu prepared all clinical serum samples and performed the flow cytometric analysis. All authors participated in the drafting and revision of the manuscript.

Acknowledgements

We thank the Fundamental Research Funds for the Central Universities (No. YJ201975), the National Natural Science Foundation of China $(22006104,22074099)$, and the Sichuan Science and Technology Project (2021YJ0322) for financial supports.

\section{References}

1. WHO Director-General's opening remarks at the media briefing on COVID-19-11 March 2020 (2020).

2. Kaminski, M. M., Abudayyeh, O. O., Gootenberg, J. S., Zhang, F., Collins, J. J. CRISPR-based diagnostics. Nat. Biomed. Eng. 5, 643-656 (2021).

3. Tang, Y. N., Gao, L., Feng, W., Guo, C., Yang, Q. F., Li, F., Le, X. C. The CRISPR-Cas toolbox for analytical and diagnostic assay development. Chem. Soc. Rev. 50, 11844-11869 (2021).

4. Broughton, J. P., Deng, X., Yu, G., Fasching, C. L., Servellita, V., Singh, J., Miao, X., Streithorst, J. A., Granados, A., Sotomayor-Gonzalez, A., Zorn, K., Gopez, A., Hsu, E., Gu, W., Miller, S., Pan, C. Y., Guevara, H., Wadford, D. A., Chen, J. S., Chiu, C. Y. CRISPR-Cas12-based detection of SARS-CoV-2. Nat. Biotechnol. 38, 870-874 (2020).

5. Joung, J., Ladha, A., Saito, M., Kim, N. G., Woolley, A. E., Segel, M., Barretto, R. P. J., Ranu, A., Macrae, R. K., Faure, G., loannidi, E. I., Krajeski, R. N., Bruneau, R., Huang, M. L. W., Yu, X. G., Li, J. Z., Walker, B. D., Hung, D. T., Greninger, A. L., Jerome, K. R., Gootenberg, J. S., Abudayyeh, O. O., Zhang, F., Detection of SARS-CoV-2 with SHERLOCK One-Pot Testing. New. Engl. J. Med. 383, 1492-1494 (2020).

6. Long, Q. X., Tang, X. J., Shi, Q. L., Li, Q., Deng, H. J., Yuan, J., Hu, J. L., Xu, W., Zhang, Y., Lv, F. J., Su, K., Zhang, F., Gong, J., Wu, B., Liu, X. M., Li, J. J., Qiu, J. F., Chen, J., Huang, A. L. Clinical and immunological assessment of asymptomatic SARS-CoV-2 infections. Nat. Med. 26, 1200-1204 (2020).

7. Long, Q. X., Liu, B. Z., Deng, H. J., Wu, G. C., Deng, K., Chen, Y. K., Liao, P., Qiu, J. F., Lin, Y., Cai, X. F., Wang, D. Q., Hu, Y., Ren, J. H., Tang, N., Xu, Y. Y., Yu, L. H., Mo, Z., Gong, F., Zhang, X. L., Tian, W. G., Hu, L., Zhang, X. X., Xiang, J. L., Du, H. X., Liu, H. W., Lang, C. H., Luo, X. H., Wu, S. B., Cui, X. P., Zhou, Z., Zhu, M. M., Wang, J., Xue, C. J., Li, X. F., Wang, L., Li, Z. J., Wang, K., Niu, C. C., Yang, Q. J., Tang, X. J., Zhang, Y., 
Liu, X. M., Li, J. J., Zhang, D. C., Zhang, F., Liu, P., Yuan, J., Li, Q., Hu, J. L., Chen, J., Huang, A. L. Antibody responses to SARS-CoV-2 in patients with COVID-19. Nat. Med. 26, 845-848 (2020).

8. Xia, W., Li, M., Wang, Y., Kazis, L. E., Berlo, K., Melikechi, N., Chiklis, G. R. Longitudinal analysis of antibody decay in convalescent COVID-19 patients. Sci. Rep. 11, 16796 (2021).

9. Ainsworth, M., The National SARS-CoV-2 Serology Assay Evaluation Group. Performance characteristics of five immunoassays for SARS-CoV-2: a head-to-head benchmark comparison (vol 20, pg 1390, 2020). Lancet. Infect. Dis. 20, E298-E298 (2020).

10. GeurtsvanKessel, C. H., Okba, N. M. A., Igloi, Z., Bogers, S., Embregts, C. W. E., Laksono, B. M., Leijten, L., Rokx, C., Rijnders, B., Rahamat-Langendoen, J., van den Akker, J. P. C., van Kampen, J. J. A., van der Eijk, A. A., van Binnendijk, R. S., Haagmans, B., Koopmans, M. An evaluation of COVID-19 serological assays informs future diagnostics and exposure assessment. Nat. Commun. 11, 3436 (2020).

11. Rhoads, D. D., Cherian, S. S., Roman, K., Stempak, L. M., Schmotzer, C. L., Sadri, N. Comparison of Abbott ID Now, DiaSorin Simplexa, and CDC FDA Emergency Use Authorization Methods for the Detection of SARS-CoV-2 from Nasopharyngeal and Nasal Swabs from Individuals Diagnosed with COVID-19. J. Clin. Microbiol. 58, e00760-20 (2020).

12. Whitman, J. D., Hiatt, J., Mowery, C. T., Shy, B. R., Yu, R., Yamamoto, T. N., Rathore, U., Goldgof, G. M., Whitty, C., Woo, J. M., Gallman, A. E., Miller, T. E., Levine, A. G., Nguyen, D. N., Bapat, S. P., Balcerek, J., Bylsma, S. A., Lyons, A. M., Li, S., Wong, A. W. Y., Gillis-Buck, E. M., Steinhart, Z. B., Lee, Y., Apathy, R., Lipke, M. J., Smith, J. A., Zheng, T. N., Boothby, I. C., Isaza, E., Chan, J., Acenas, D. D., Lee, J. W., Macrae, T. A., Kyaw, T. S., Wu, D. V., Ng, D. L., Gu, W., York, V. A., Eskandarian, H. A., Callaway, P. C., Warrier, L., Moreno, M. E., Levan, J., Torres, L., Farrington, L. A., Loudermilk, R. P., Koshal, K., Zorn, K. C., Garcia-Beltran, W. F., Yang, D., Astudillo, M. G., Bernstein, B. E., Gelfand, J. A., Ryan, E. T., Charles, R. C., lafrate, A. J., Lennerz, J. K., Miller, S., Chiu, C. Y., Stramer, S. L., Wilson, M. R., Manglik, A., Ye, C. J., Krogan, N. J., Anderson, M. S., Cyster, J. G., Ernst, J. D., Wu, A. H. B., Lynch, K. L., Bern, C., Hsu, P. T. D., Marson, A. Evaluation of SARSCoV-2 serology assays reveals a range of test performance. Nat. Biotechnol. 38, 1174-1183 (2020).

13. Lee, A. R. Y. B., Wong, S. Y., Chai, L. Y. A., Lee, S. C., Lee, M., Muthiah, M. D., Tay, S. H., Teo, C. B., Tan, B. K. J., Chan, Y. H., Sundar, R., Soon, Y. Y. Efficacy of COVID-19 vaccines in immunocompromised patients: A systematic review and meta-analysis.

MedRxiv. https://doi.org/10.1101/2021.09.28.21264126 (2021).

14. Embi, P. J., Levy, M. E., Naleway, A. L., Patel, P., Gaglani, M., Natarajan, K., Dascomb, K., Ong, T. C., Klein, N. P., Liao, I. C., Grannis, S. J., Han, J., Stenehjem, E., Dunne, M. M., Lewis, N., Irving, S. A., Rao, S., McEvoy, C., Bozio, C. H., Murthy, K., Dixon, B. E., Grisel, N., Yang, D. H., Goddard, K., Kharbanda, A. B., Reynolds, S., Raiyani, C., Fadel, W. F., Arndorfer, J., Rowley, E. A., Fireman, B., Ferdinands, J., Valvi, N. R., Ball, S. W., Zerbo, O., Griggs, E. P., Mitchell, P. K., Porter, R. M., Kiduko, S. A., Blanton, L., Zhuang, Y., Steffens, A., Reese, S. E., Olson, N., Williams, J., Dickerson, M., McMorrow, M., Schrag, S. J., Verani, J. R., 
Fry, A. M., Azziz-Baumgartner, E., Barron, M. A., Thompson, M. G., DeSilva, M. B. Effectiveness of 2-Dose Vaccination with mRNA COVID-19 Vaccines Against COVID-19 - Associated Hospitalizations Among Immunocompromised Adults - Nine States, January-September 2021. MMWR Morb. Mortal. Wkly. Rep. 2021 70, 1553-1559 (2021).

15. Elledge, S. K., Zhou, X. X., Byrnes, J. R., Martinko, A. J., Lui, I., Pance, K., Lim, S. A., Glasgow, J. E., Glasgow, A. A., Turcios, K., lyer, N. S., Torres, L., Peluso, M. J., Henrich, T. J., Wang, T. T., Tato, C. M., Leung, K. K., Greenhouse, B., Wells, J. A. Engineering luminescent biosensors for point-of-care SARS-CoV-2 antibody detection. Nat. Biotechnol. 39, 928-935 (2021).

16. Yao, Z., Drecun, L., Aboualizadeh, F., Kim, S. J., Li, Z. J., Wood, H., Valcourt, E. J., Manguiat, K., Plenderleith, S., Yip, L., Li, X. L., Zhong, Z., Yue, F. Y., Closas, T., Snider, J., Tomic, J., Drews, S. J., Drebot, M. A., McGeer, A., Ostrowski, M., Mubareka, S., Rini, J. M., Owen, S., Stagljar, I. A homogeneous split-luciferase assay for rapid and sensitive detection of anti-SARS CoV-2 antibodies. Nat. Commun. 12, 1806 (2021).

17. Zhang, W., Du, R. H., Li, B., Zheng, X. S., Yang, X. L., Hu, B., Wang, Y. Y., Xiao, G. F., Yan, B., Shi, Z. L., Zhou, P. Molecular and serological investigation of 2019-nCoV infected patients: implication of multiple shedding routes. Emerg. Microbes. Infec. 9, 386-389 (2020).

18. Caillard, S., Thaunat, O. COVID-19 vaccination in kidney transplant recipients. Nat. Rev. Nephrol. 12, 785-787 (2021).

19. Sattler, A., Schrezenmeier, E., Weber, U. A., Potekhin, A., Bachmann, F., Straub-Hohenbleicher, H., Budde, K., Storz, E., Pross, V., Bergmann, Y., Thole, L. M., Tizian, C., Holsken, O., Diefenbach, A., Schrezenmeier, H., Jahrsdorfer, B., Zemojtel, T., Jechow, K., Conrad, C., Lukassen, S., Stauch, D., Lachmann, N., Choi, M., Halleck, F., Kotsch, K. Impaired humoral and cellular immunity after SARS-CoV-2 BNT162b2 (tozinameran) prime-boost vaccination in kidney transplant recipients. J. Clin. Invest. 131, e150175 (2021).

20. Danthu, C., Hantz, S., Dahlem, A., Duval, M., Ba, B., Guibbert, M., El Ouafi, Z., Ponsard, S., Berrahal, I., Achard, J. M., Bocquentin, F., Allot, V., Rerolle, J. P., Alain, S., Toure, F. Humoral Response after SARS-CoV-2 mRNA Vaccination in a Cohort of Hemodialysis Patients and Kidney Transplant Recipients. J. Am. Soc. Nephrol. 32, 2153-2158 (2021).

21. Rincon-Arevalo, H., Choi, M., Stefanski, A. L., Halleck, F., Weber, U., Szelinski, F., Jahrsdorfer, B., Schrezenmeier, H., Ludwig, C., Sattler, A., Kotsch, K., Potekhin, A., Chen, Y., Burmester, G. R., Eckardt, K. U., Guerra, G. M., Durek, P., Heinrich, F., Ferreira-Gomes, M., Radbruch, A., Budde, K., Lino, A. C., Mashreghi, M. F., Schrezenmeier, E., Dorner, T. Impaired humoral immunity to SARS-CoV-2 BNT162b2 vaccine in kidney transplant recipients and dialysis patients. Sci. Immunol. 6, eabj1031 (2021).

22. Bruminhent, J., Setthaudom, C., Chaumdee, P., Boongird, S., Kiertiburanakul, S., Malathum, K., Nongnuch, A., Phuphuakrat, A., Jirasiritham, S., Janphram, C., Thotsiri, S., Upama, S., Assanatham, M. SARS-CoV-2-specific Humoral and Cell-mediated Immune Responses after Immunization with Inactivated 
COVID-19 Vaccine in Kidney Transplant Recipients. Am. J. Transplant. https://doi.org/ 10.1111/ajt.16867 (2021).

23. Benotmane, I., Gautier, G., Perrin, P., Olagne, J., Cognard, N., Fafi-Kremer, S., Caillard, S. Antibody Response After a Third Dose of the mRNA-1273 SARS-CoV-2 Vaccine in Kidney Transplant Recipients With Minimal Serologic Response to 2 Doses. JAMA 326, 1063-1065 (2021).

24. Kidney Disease: Improving Global Outcomes (KDIGO) Transplant Work Group. KDIGO clinical practice guideline for the care of kidney transplant recipients. Am. J. Transplant. 9, S1-155 (2009).

25. Sureshchandra, S., Lewis, S. A., Doratt, B., Jankeel, A., Coimbra Ibraim, I., Messaoudi, I. Single cell profiling of T and B cell repertoires following SARS-CoV-2 mRNA vaccine. JCI Insight. 6, e153201 (2021).

26. Tong, R., Zhong, J., Li, R., Chen, Y., Hu, L., Li, Z., Shi, J., Lin, G., Lyu, Y., Hu, L., Guo, X., Liu, Q., Shuang, T., Zhang, C., Yuan, A., Zhang, M., Lin, W., Pu, J. Characterizing cellular and molecular variabilities of peripheral immune cells in healthy inactivated SARS-CoV-2 vaccine recipients by single-cell RNA sequencing. MedRxiv. https://doi.org/10.1101/2021.05.06.21256781 (2021).

27. Su, S. C., Yang, T. J., Yu, P. Y., Liang, K. H., Chen, W. Y., Yang, C. W., Lin, H. T., Wang, M. J., Lu, R. M., Tso, H. C., Chung, M. J., Hsieh, T. Y., Chang, Y. L., Lin, S. C., Hsu, F. Y., Ke, F. Y., Wu, Y. H., Hwang, Y. C., Liu, I. J., Liang, J. J., Liao, C. C., Ko, H. Y., Sun, C. P., Wu, P. Y., Jan, J. T., Chang, Y. C., Lin, Y. L., Tao, M. H., Hsu, S. T., Wu, H. C. Structure-guided antibody cocktail for prevention and treatment of COVID-19. Plos. Pathog. 17, e1009704 (2021).

28. Norman, M., Gilboa, T., Ogata, A. F., Maley, A. M., Cohen, L., Busch, E. L., Lazarovits, R., Mao, C. P., Cai, Y. F., Zhang, J., Feldman, J. E., Hauser, B. M., Caradonna, T. M., Chen, B., Schmidt, A. G., Alter, G., Charles, R. C., Ryan, E. T., Walt, D. R. Ultrasensitive high-resolution profiling of early seroconversion in patients with COVID-19. Nat. Biomed. Eng. 4, 1180-1187 (2020).

29. Ter-Ovanesyan, D., Gilboa, T., Lazarovits, R., Rosenthal, A., Yu, X., Li, J. Z., Church, G. M., Walt, D. R. Ultrasensitive Measurement of Both SARS-CoV-2 RNA and Antibodies from Saliva. Anal. Chem. 93, 53655370 (2021).

30. Lundberg, M., Eriksson, A., Tran, B., Assarsson, E., Fredriksson, S. Homogeneous antibody-based proximity extension assays provide sensitive and specific detection of low-abundant proteins in human blood. Nucleic. Acids. Res. 39, e102 (2011).

31. Dagur, P. K., McCoy, J. P. Jr. Collection, Storage, and Preparation of Human Blood Cells. Curr. Protoc. Cytom. 73, https://doi.org/10.1002/0471142956.cy0501s73 (2015).

32. Streitz, M., Miloud, T., Kapinsky, M., Reed, M. R., Magari, R., Geissler, E. K., Hutchinson, J. A., Vogt, K., Schlickeiser, S., Kverneland, A. H., Meisel, C., Volk, H. D., Sawitzki, B. Standardization of whole blood 
immune phenotype monitoring for clinical trials: panels and methods from the ONE study. Transplant. Res. 2, 17 (2013).

33. Kverneland, A. H., Streitz, M., Geissler, E., Hutchinson, J., Vogt, K., Boes, D., Niemann, N., Pedersen, A. E., Schlickeiser, S., Sawitzki, B. Age and gender leucocytes variances and references values generated using the standardized ONE-Study protocol. Cytom. Part. A 89, 543-564 (2016).

34. Bronte, V., Brandau, S., Chen, S. H., Colombo, M. P., Frey, A. B., Greten, T. F., Mandruzzato, S., Murray, P. J., Ochoa, A., Ostrand-Rosenberg, S., Rodriguez, P. C., Sica, A., Umansky, V., Vonderheide, R. H., Gabrilovich, D. I. Recommendations for myeloid-derived suppressor cell nomenclature and characterization standards. Nat. Commun. 7, 12150 (2016).

\section{Figures}

a
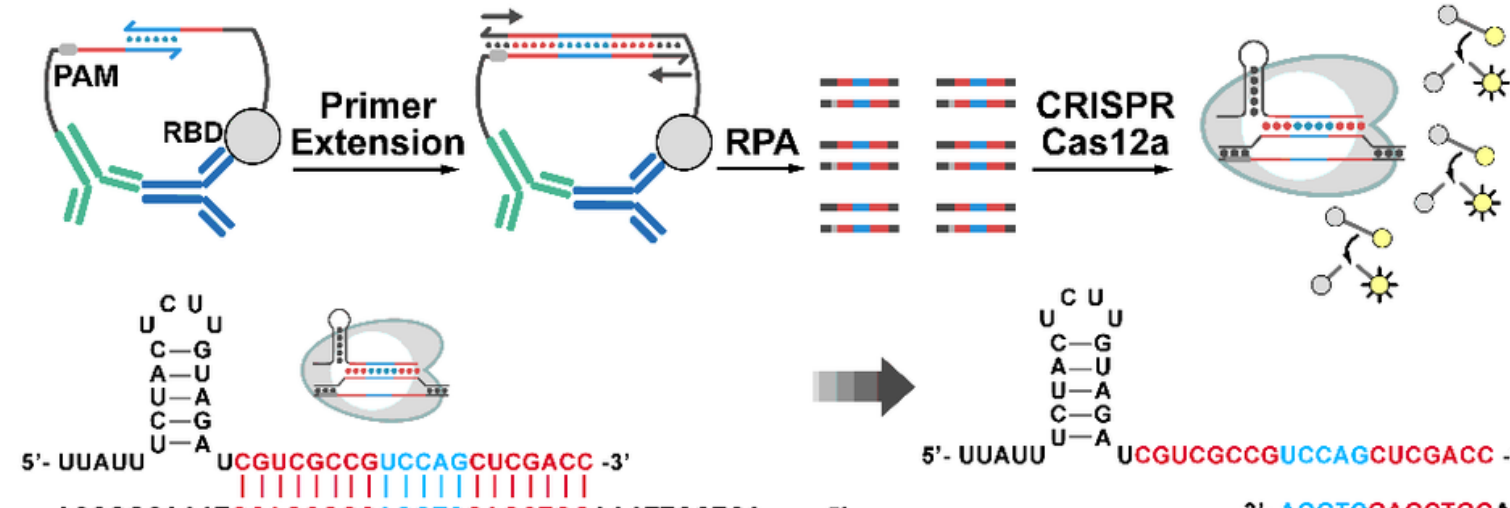

b

TS: 3 '- ......ACCGGCAAATGCAGCGGCAGGTCGAGCTGGAAATTCCTCA...... -5'

NTS: 5 ' -.....TGGCCGTTTACGTCGCCGTCCAGCTCGACCTTTAAGGAGT..... -3,

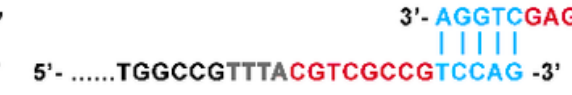

C

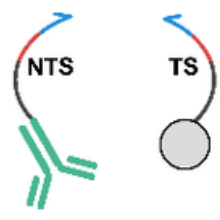

$\mathrm{Tm}=10^{\circ} \mathrm{C}$

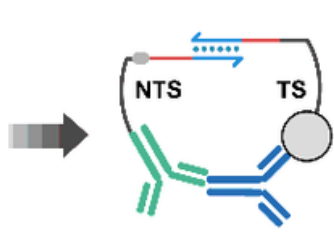

$\mathrm{Tm}>37^{\circ} \mathrm{C}$

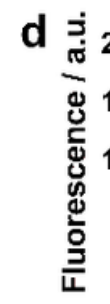

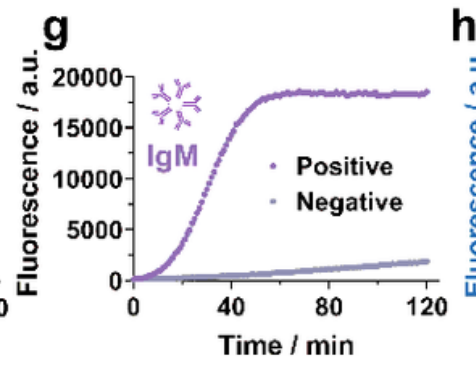

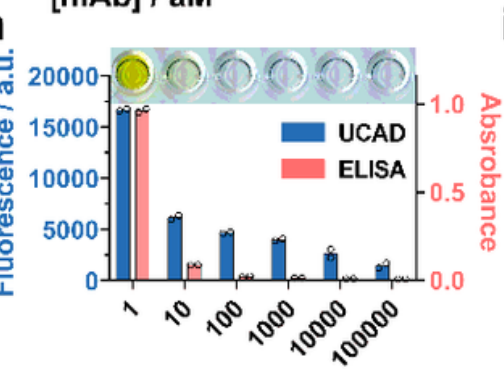

Dilution factor

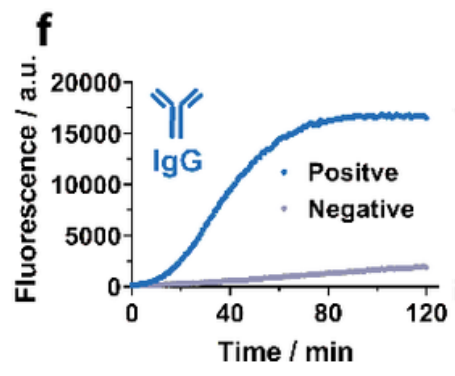

Figure 1

(a) Schematic illustration of the workflow of the UCAD assay. (b) Sequence design of the dsDNA template for triggering the collateral cleavage activity of CRISPR-Cas12a, as well as the strategy to split the dsDNA 
template into TS and NTS probes for UCAD. (c) Proximity binding of the two UCAD probes to the same anti-RBD antibody through affinity motifs enhances the $T_{m}$ of the duplex domain from $10{ }^{\circ} \mathrm{C}$ to $46^{\circ} \mathrm{C}$ and thus enables the stable binding between TS and NTS probes. (d) A calibration curve for the detection of anti-SARS-CoV-2 spike protein RBD human mAb (clone: OTIH401) in the range of 1 aM to $1 \mathrm{pM}$ was established by plotting fluorescence intensity at $40 \mathrm{~min}$ of the CRISPR-Cas12a reaction as a function of target concentrations, which was also compared with UCAD without RPA amplification. Each error bar represents one standard deviation from triplicate analyses. (e) Detection of the target anti-human RBD and closely related nontargeted anti-SARS-CoV-2 nucleocapsid (N) protein human mAb and anti-SARSCoV-2 spike protein RBD rabbit pAb at a concentration of $10 \mathrm{fM}$ using UCAD. (f, $\mathbf{g})$ Kinetic curves for the detection of anti-RBD IgG (f) and IgM (g)in commercially purchased certified anti-SARS-CoV-2 IgG/lgM positive and negative serum samples using UCAD. $(\mathbf{h}$, i) Detection of anti-RBD IgG $(h)$ and IgM (i) in certified anti-SARS-CoV-2 IgG/lgM positive serum diluted in negative human serum with dilution factors from 1 to 100,000 using both UCAD and commercial ELISA kits. 


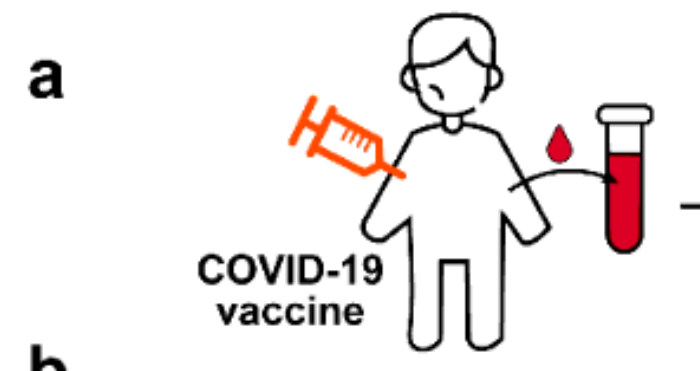

b

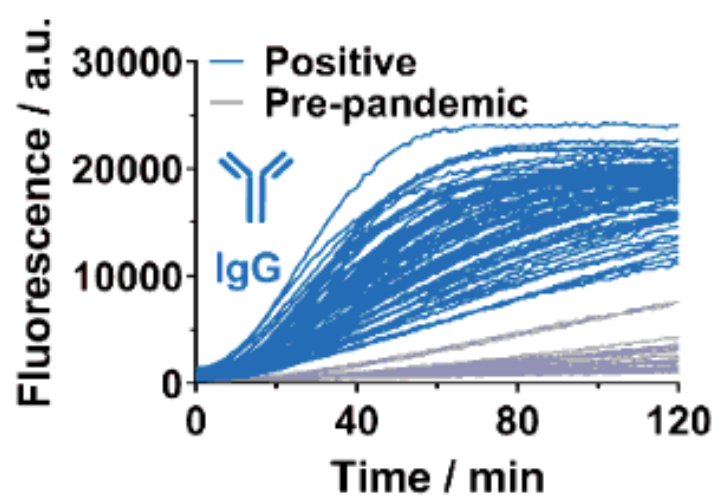

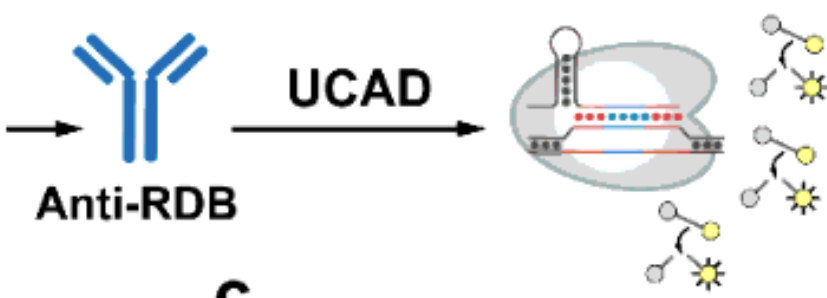

C

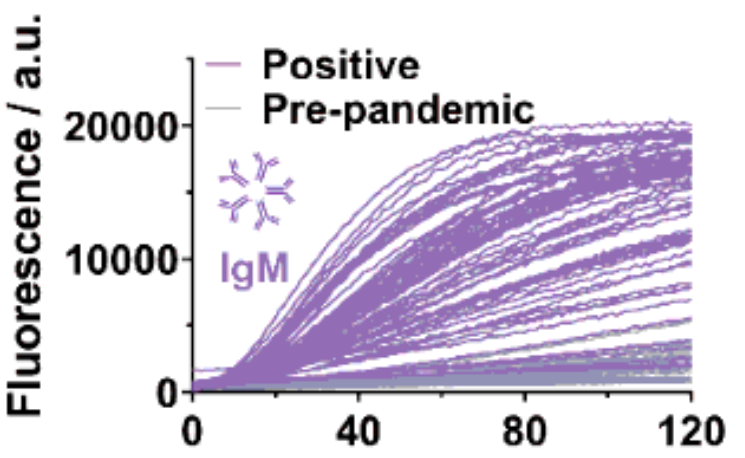

Time / $\mathrm{min}$

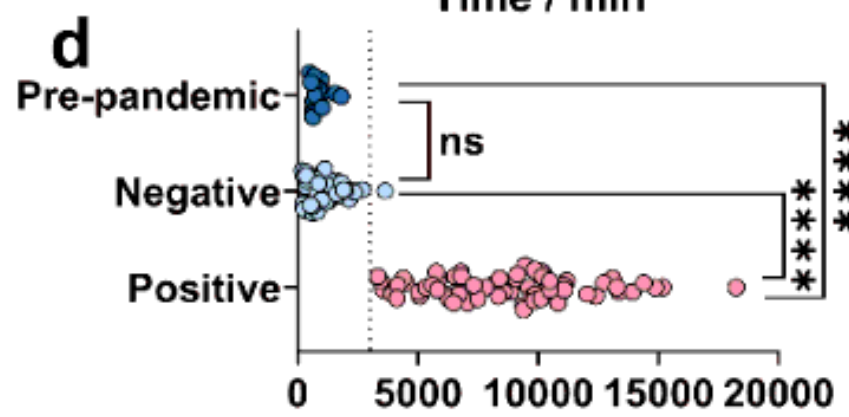

Fluorescence / a.u.
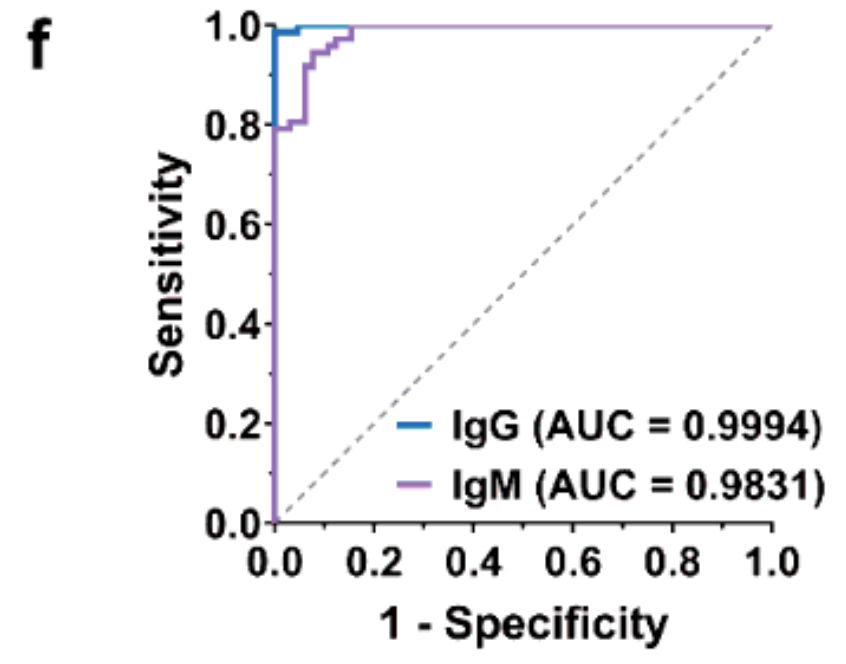

e

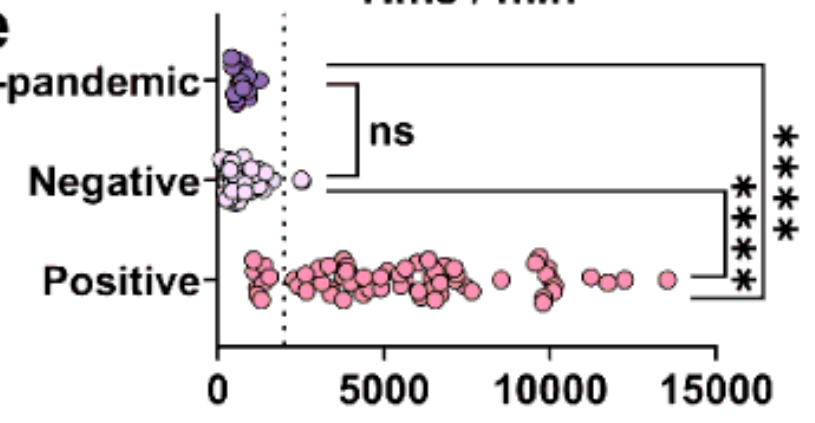

Fluorescence / a.u.

g

CLIA (Total antibody)

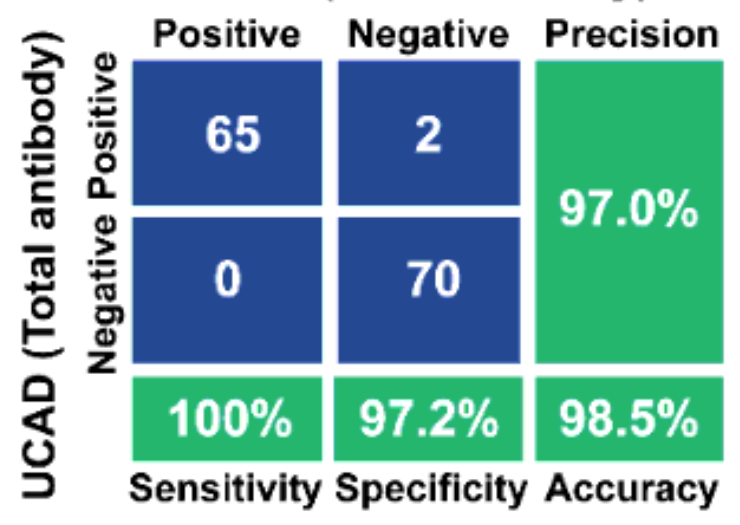

Figure 2

(a) Schematic illustration of the workflow for clinical validation of UCAD. (b, c) Kinetic curves for the detection of anti-RBD IgG (b) and IgM (c) in 65 anti-RBD positive sera collected from healthy individuals who received two shots of inactivated COVID-19 vaccine and 17 pre-pandemic sera. (d, e) Endpoint fluorescence signals at 40 min of three clinical cohorts, including17 pre-pandemic samples, 65 positive samples and 55 presumptive negative sera collected during the pandemic. Both the anti-RBD $\lg G$ and $\lg M$ 
levels of the positive cohort $(n=65)$ were significantly higher than those of the pre-pandemic and pandemic negative cohorts $(p<0.0001)$. The pre-pandemic and pandemic negative cohorts had no significant difference ( $p=0.1090$ for $\lg G$ and $p=0.2023$ for IgM using unpaired t-test) and were thus combined as one negative group ( $n=72$ ) to determine cutoffs for distinguishing positive and negative results in UCAD. (f) ROC curves of the UCAD assay for detecting anti-RBD IgG and IgM in 137 human serum samples (positive: $n=65$, negative: $n=72$ ). Optimal cutoff fluorescence values were selected through ROC analysis: 3007 a.u. at 40 min for anti-RBD IgG (specificity $=100 \%$, sensitivity $=98.61 \%$ ) and 1973 a.u. at 40 min for anti-RBD $\operatorname{lgM}$ (specificity $=87.69 \%$, sensitivity $=97.22 \%$ ). (g) Evaluation of the clinical sensitivity and specificity of UCAD compared to the standard CLIA test using a confusion matrix ( $n=72$ for negative sera and $n=65$ for positive sera).

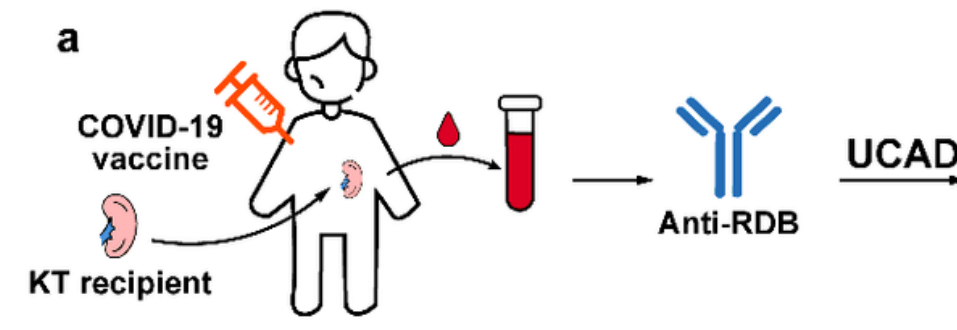

b
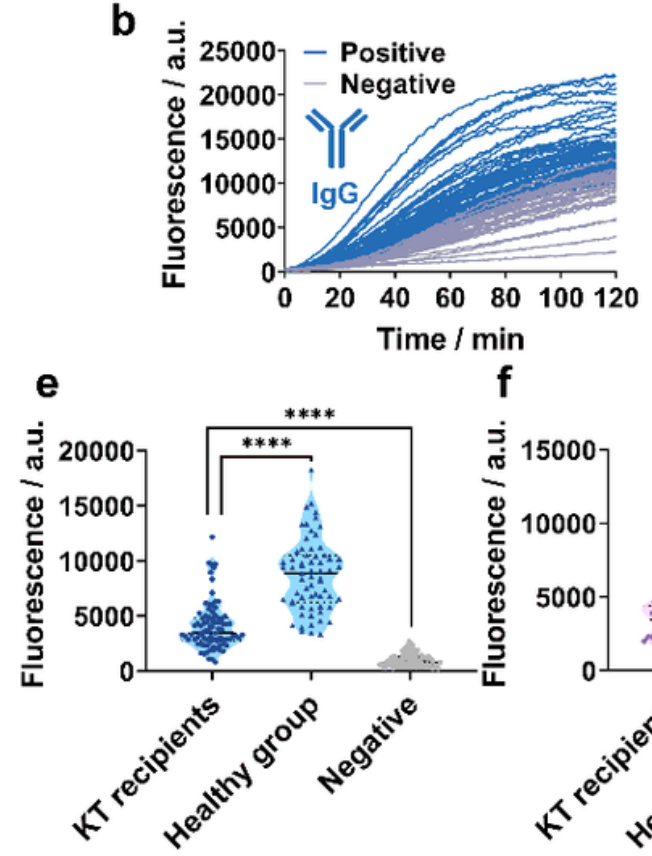

f

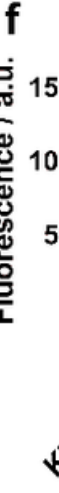

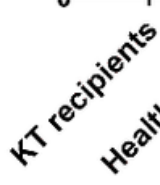

C

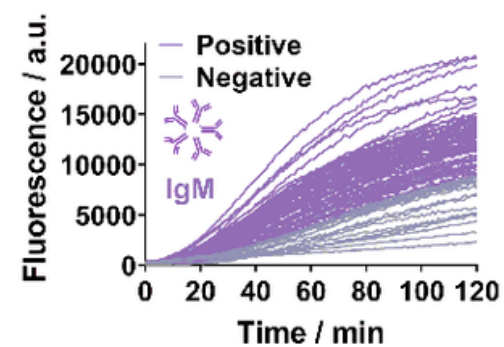

g

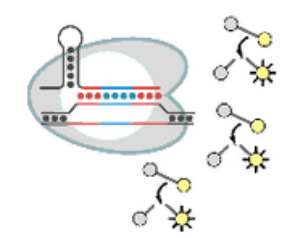

d

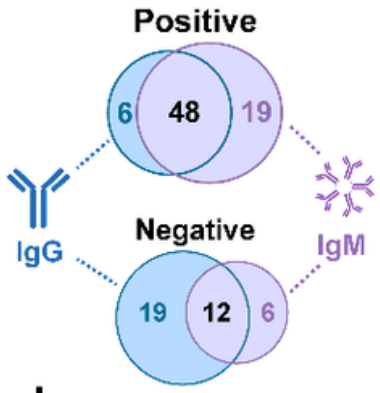

h

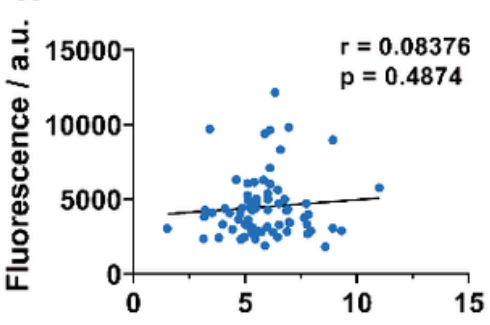

Tac before vaccination / $\mathrm{ng} / \mathrm{mL}$

Figure 3

(a) Schematic illustration of the UCAD workflow for analyzing the levels of anti-RBD IgG and IgM in clinical serum samples collected from KTR patients who had received a triad immunosuppression regimen and two doses of inactivated COVID-19 vaccine. $(\mathbf{b}, \mathbf{c})$ Kinetic curves for the detection of antiRBD IgG (b) and IgM (c) in sera of 85 KTRs. (d) Venn diagrams to illustrate the distribution of positive and negative anti-RBD IgG and IgM test results in 85 KTRs. (e, f) Violin plots of end-point fluorescence signals at 40 min for detecting anti-RBD IgG (e) and IgM (f) in 85 sera collected from KTRs, 65 positive sera collected from vaccinated healthy individuals, and 72 negative sera. The levels of both anti-RBD IgG and IgM in the KTR cohort were significantly different from those in the healthy and negative cohorts $(p<$ 
0.0001). ( $\mathbf{g}, \mathbf{h})$ Pearson correlation analysis to evaluate the correlation between UCAD-determined IgM ( $\mathbf{g})$ and IgG $(\mathbf{h})$ levels and the levels of TAC trough $(\mathrm{ng} / \mathrm{mL})$ in the $85 \mathrm{KTR}$ cohort.

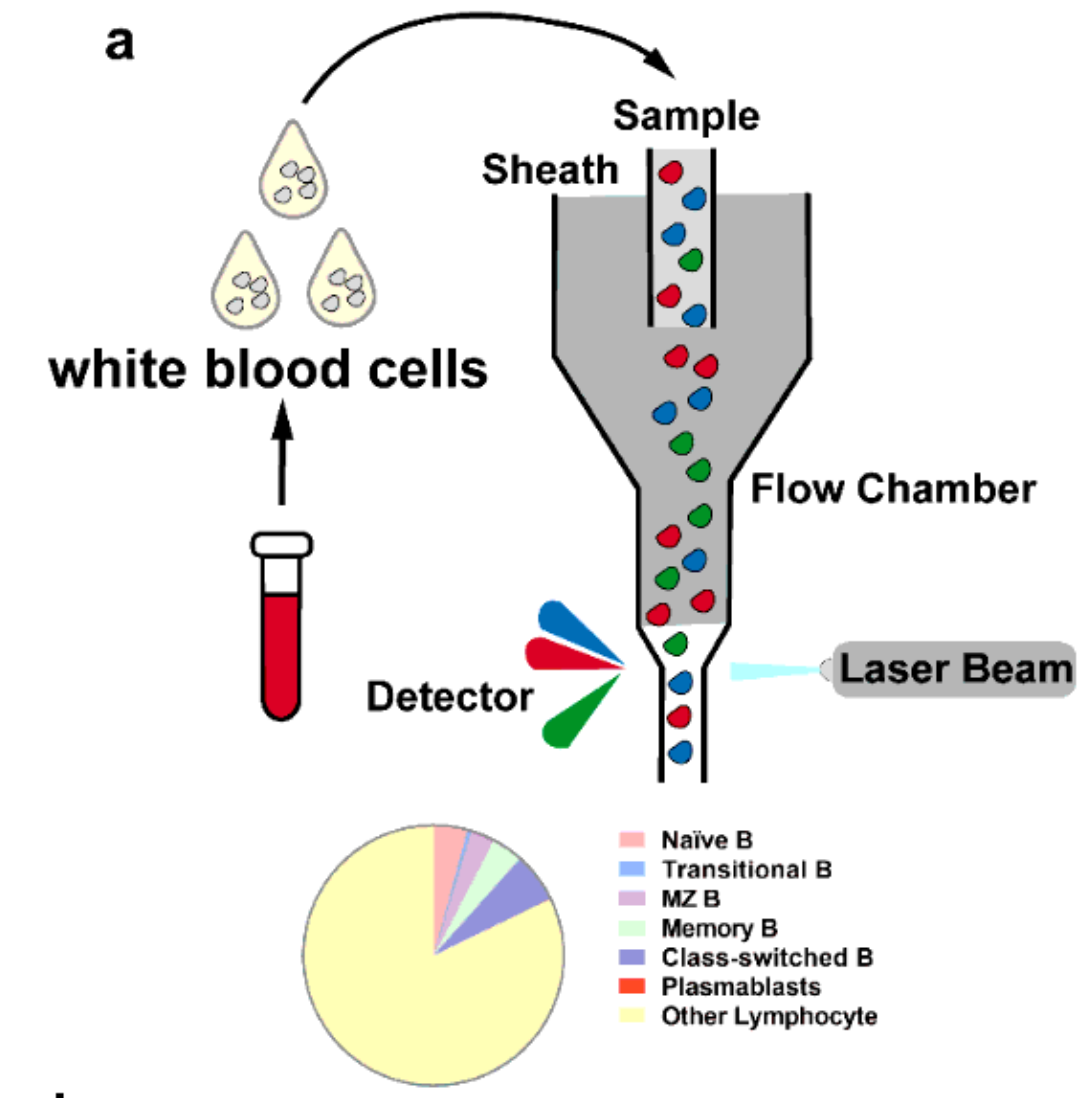

b

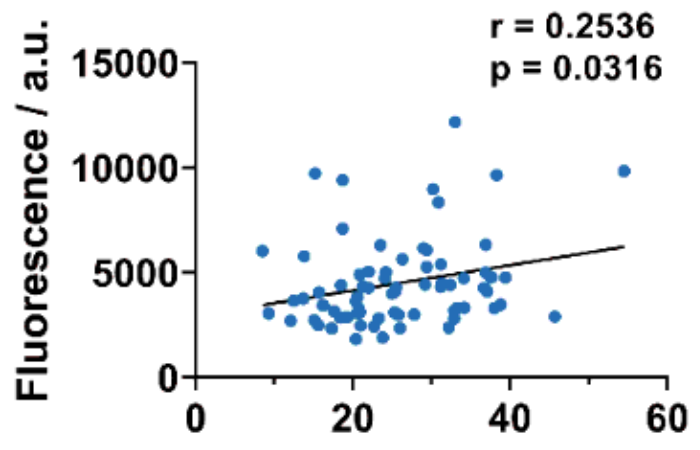

Lymphocyte\% before vaccination

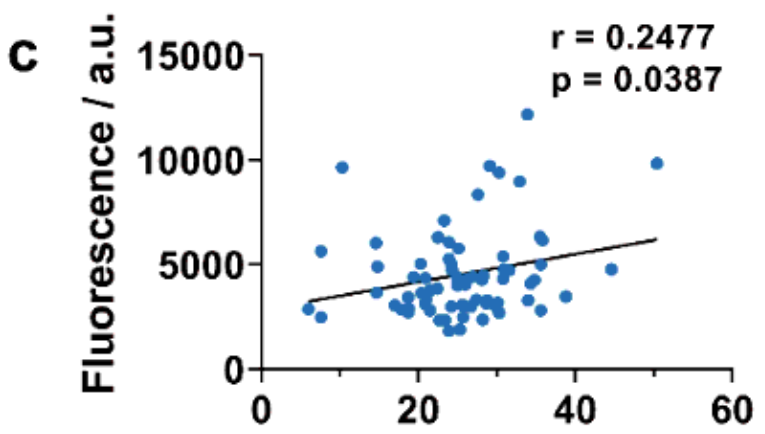

Lymphocyte\% after vaccination

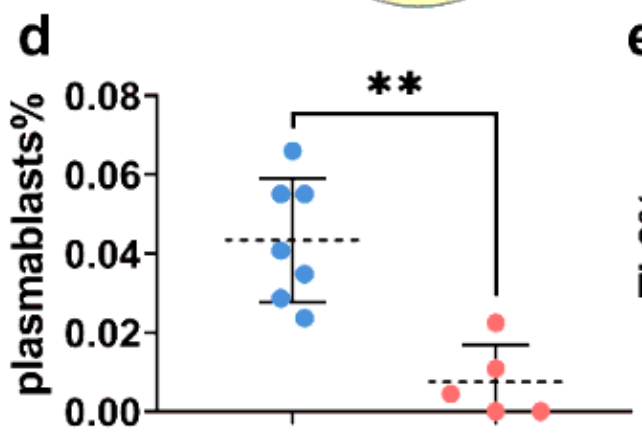

e
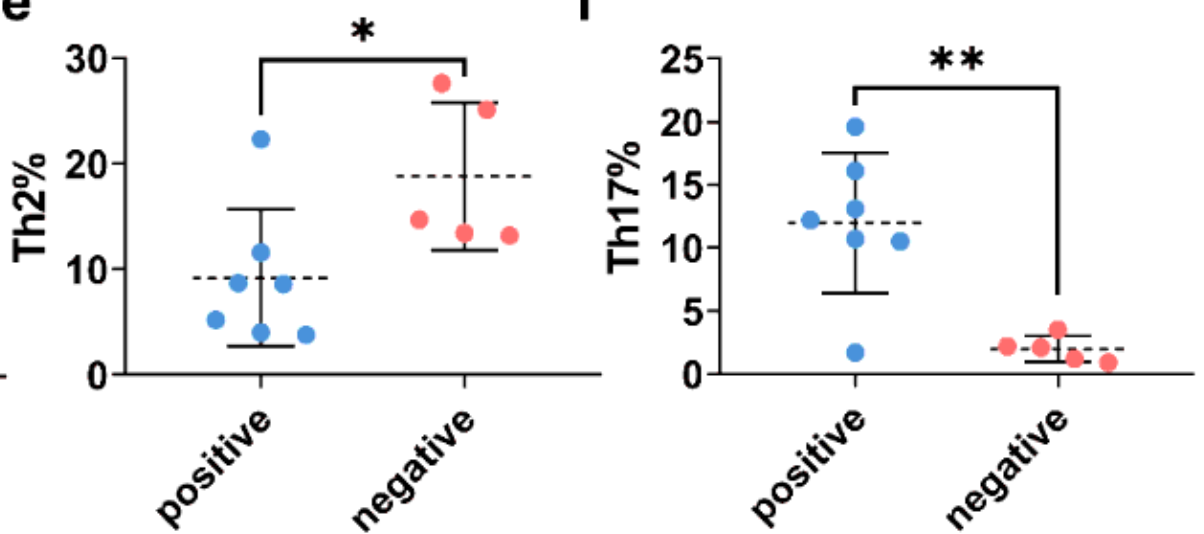

Figure 4

(a) Schematic illustration of flow cytometric analysis of white blood cells (WBCs) in UCAD-determined anti-RBD positive and negative KTRs (b, $\mathbf{c}$ ) Correlations between the UCAD-determined anti-RBD IgG levels and lymphocyte percentage in WBCs before (b) and after (c) vaccination. The IgG levels were weakly positively correlated with the lymphocyte levels before $(n=73, r=0.2536, p=0.0316)$ and after vaccination ( $n=73, r=0.2477, p=0.0387)$. (d) The percentage composition of plasmablasts in lymphocytes of 7 randomly chosen $\operatorname{lgG}^{+} / \operatorname{lgM}^{+}$KTRs and 5 randomly chosen $\operatorname{lgG}^{-} / \operatorname{lgM}^{-} \mathrm{KTR}^{-}$. Unpaired ttests showed that the $\operatorname{lgG} / / \mathrm{lgM}^{-} \mathrm{KTR}$ cohort had significantly lower plasmablast levels than the $\operatorname{lgG}^{+} / \mathrm{lgM}^{+}$ KTR cohort $(p=0.0014)$. (e) The percentage composition of Th2 cells in $C D 4^{+}$cells of the $7 \mathrm{IgG}^{+} / \mathrm{IgM}^{+}$ 


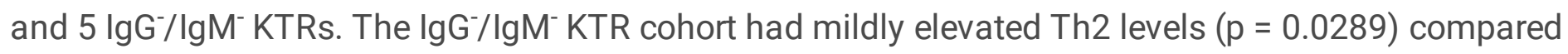
with the $\mathrm{IgG}^{+} / \operatorname{lgM}^{+}$KTR cohort. (f) The percentage composition of Th17 cells in CD4 ${ }^{+}$cells of the 7 $\operatorname{lgG}^{+} / \mathrm{IgM}^{+}$and $5 \mathrm{IgG}^{-} / \mathrm{IgM}^{-} \mathrm{KTRs}^{-}$. The $\mathrm{IgG}^{-} / \mathrm{IgM}^{-} \mathrm{KTR}^{-}$cohort had substantially reduced Th17 levels $(\mathrm{p}=$ 0.0016) compared with the $\operatorname{lgG}^{+} / \operatorname{lgM}^{+} \mathrm{KTR}$ group.

\section{Supplementary Files}

This is a list of supplementary files associated with this preprint. Click to download.

- Supplementarylnformation.pdf 